\title{
(2) OPEN ACCESS \\ National rates of non-fatal emergency department visits and hospitalisations due to fall-related injuries in older adults 2010-2014 and 2016: transitioning from ICD-9-CM to ICD-10-CM
}

\author{
Briana L Moreland (1) , ${ }^{1,2}$ Elizabeth R Burns, ${ }^{2}$ Yara K Haddad (1) 2,3
}

${ }^{1}$ Synergy America Inc, Duluth, Georgia, USA

${ }^{2}$ National Center for Injury Prevention and Control, Centers for Disease Control and Prevention, Atlanta, Georgia, USA

${ }^{3}$ TJFACT, Atlanta, Georgia, USA

\section{Correspondence to}

Briana L Moreland, Centers for Disease Control and Prevention, Atlanta, GA 30333, USA; bmoreland@cdc.gov

Received 10 December 2019 Revised 6 October 2020 Accepted 8 October 2020
Check for updates

(C) Author(s) (or their employer(s)) 2021. Re-use permitted under CC BY-NC. No commercial re-use. See rights and permissions. Published by BMJ.

To cite: Moreland $\mathrm{BL}$, Burns ER, Haddad YK. Inj Prev 2021:27:i75-i78.

\begin{abstract}
Background This study describes rates of non-fatal fall-injury emergency department (ED) visits and hospitalisations before and after the US 2015 transition from the 9th to 10th revision of the International Classification of Diseases, Clinical Modification (ICD-9CM to ICD-10-CM).
\end{abstract}

Methods ED visit and hospitalisation data for adults aged 65+ years were obtained from the 2010-2016 Healthcare Cost and Utilisation Project. Differences in fall injury rates between 2010 and 2014 (before transition), and 2014 and 2016 (before and after transition) were analysed using t-tests.

Results For ED visits, rates did not differ significantly between 2014 and 2016 (4288 vs 4318 per 100 000, respectively). Hospitalisation rates were lower in 2014 (1232 per 100000 ) compared with 2016 (1281 per 100 000).

Conclusion Increased rates of fall-related hospitalisations could be an artefact of the transition or may reflect an increase in the rate of fall-related hospitalisations. Analyses of fall-related hospitalisations across the transition should be interpreted cautiously.

\section{INTRODUCTION}

Over one-quarter of older adults (aged 65+) fall each year and about 1 in 10 report a fall injury requiring medical attention or restricted activity for at least a day. ${ }^{1}$ Falls account for approximately $60 \%$ of injury-related emergency department (ED) visits in older adults each year. ${ }^{2}$ Many of these injuries lead to loss of function and prolonged use of healthcare services. ${ }^{13}$ Quantifying fall injuries among older adults over time is important to understanding the burden on the healthcare system.

On 1 October 2015, the USA transitioned from the International Classification of Diseases, 9th Revision, Clinical Modification (ICD-9-CM) to the 10th Revision (ICD-10-CM) for clinical coding in medical settings. ${ }^{4}$ In medical records, coding is required for clinical documentation and billing. ${ }^{5}$ The number of codes for all conditions and procedures increased from 17000 in ICD-9-CM to 155000 in ICD-10-CM. ${ }^{6}$ A large portion of this increase was due to added detail for injury codes which increased from $15 \%$ of codes in ICD-9-CM to almost $60 \%$ in ICD-10-CM. ${ }^{6}$ Codes included in the falls case definition increased from 9 codes in
ICD-9-CM to 19 in ICD-10-CM. The new coding potentially expands disease conditions and sequelae specificity. ${ }^{7}$

Our study describes age-adjusted rates of nonfatal fall-related injuries treated in EDs and hospitals from 2010 to 2014 and 2016 and compares rates before and after the ICD-10-CM transition.

\section{METHODS}

Data from the 2010 to 2014, and 2016 Agency for Healthcare Research and Quality Healthcare Cost and Utilisation Project (HCUP) Nationwide Emergency Department Sample (NEDS) and the Nationwide Inpatient Sample (NIS) were analysed to determine the rate of non-fatal ED visits and hospitalisations for fall injuries among older adults (https://www.hcup-us.ahrq.gov/). Data from 2015 were excluded because the transition from ICD-9-CM to ICD-10-CM occurred in October of 2015. NEDS includes data from about 31 million ED visits each year representing approximately 143 million ED visits when weighted to the US population. NIS is drawn from all HCUP participating hospitals representing about 35 million weighted hospitalisations per year.

We used guidance from the National Center for Health Statistics and the National Center for Injury Prevention and Control to define diagnosis codes used to determine non-fatal fall-related injuries. ${ }^{8-11}$ For 2010-2014 data, fall-injury ED visits were defined as visits with an ICD-9-CM injury diagnosis in any diagnostic field ${ }^{10}$ and a fall-related external cause of injury E-code in any field ${ }^{11}$ (table 1). Fall-related hospitalisations for 2010-2014 were defined as visits with an ICD-9-CM injury code as the principal diagnosis and a fall-related external cause of injury E-code in any field. ${ }^{8}$ For 2016 , fallinjury ED visits were defined as visits with an injury diagnosis code (table 1 ) in any diagnostic field and a fall-related V-code or W-code as the external cause of injury in any field ${ }^{9}$ (table 1). Fall-related hospitalisations for 2016 were defined as visits with an ICD-10-CM injury code as the principal diagnosis and a fall-related V-code or W-code as the external cause of injury in any field. ED injuries were limited to only those patients treated and released from the ED. Hospitalisations were excluded if patients died in the hospital. Among older adults, external cause codes were present in 91\%-95\% of injury related 
Table 1 Criteria for selecting non-fatal fall injuries in emergency department or hospital settings, using the International Classification of Diseases, 9th and 10th Revisions, Clinical Modification (ICD-9-CM and ICD-10-CM)

\begin{tabular}{|c|c|c|c|c|}
\hline & \multicolumn{2}{|l|}{ ICD-9-CM } & \multicolumn{2}{|l|}{ ICD-10-CM } \\
\hline & Code* & Identifier & Codet & Identifier \\
\hline \multirow[t]{2}{*}{ External injury codes } & E880.0-E886.9, E888 & Unintentional fall & $\begin{array}{l}\text { V00.11-V00.89 } \\
\text { W00-W17§ } \\
\text { W18.1, W18.2, W18.3 } \\
\text { W19 }\end{array}$ & $\begin{array}{l}\text { Unintentional falls } \\
\text { Unspecified fall }\end{array}$ \\
\hline & Diagnosis Code & Identifier & Diagnosis Code $†$ & Identifier \\
\hline \multirow[t]{3}{*}{ Injury diagnosis codes } & $\begin{array}{l}800-904 \\
910-957\end{array}$ & Injury to body part & $\begin{array}{l}\text { S00-\$99 } \\
\text { T07-T34 } \\
\text { T84.04 and M97** }\end{array}$ & $\begin{array}{l}\text { Injury to body part } \\
\text { Foreign bodies, burns, corrosions, frostbite } \\
\text { Prosthetic joint injuries }\end{array}$ \\
\hline & $\begin{array}{l}960-989 \\
995.5,995.80-995.85 \\
990-994\end{array}$ & $\begin{array}{l}\text { Poisoning and toxic effects } \\
\text { Certain adverse effects, not classified } \\
\text { elsewhere } \\
\text { Other unspecified effects of external causes }\end{array}$ & T36-T76t† & $\begin{array}{l}\text { Drug poisoning, toxic substance effects, and } \\
\text { other unspecified effects }\end{array}$ \\
\hline & $\begin{array}{l}958-959 \\
905-909.2,909.4,909.9\end{array}$ & $\begin{array}{l}\text { Certain complications of trauma } \\
\text { Late effects of injuries }\end{array}$ & T79 & Complications of trauma \\
\hline
\end{tabular}

*E-codes adapted from Matrix of E-code Groupings. 2014. Centers for Disease Control and Prevention, https://www.cdc.gov/injury/wisqars/ecode_matrix.html

tCodes include all encounter types and were adapted from CSTE ICD-10-CM Injury Surveillance Toolkit https://resources.cste.org/Injury-Surveillance-Methods-Toolkit/Home/

GenerallnjuryIndicators. Accessed February 2020.

$\neq \mathrm{V}$-codes must include a sixth character $=1$.

$\S$ W16-codes must include a sixth character=2; except 16.4 and 16.9 which must include a fifth character=2 W16-codes including a sixth character=1, except 16.4 and 16.9 with

a fifth character $=1$ were excluded because these are classified as drowning/submersion injuries in the CSTE ICD-10-CM Injury Surveillance Toolkit.

ףDiagnosis codes adapted from the Injury Surveillance Work Group https://cdn.ymaws.com/www.safestates.org/resource/resmgr/imported/HospitalDischargeData.pdf.

${ }^{* *}$ T84.04 was replaced by M97 on Oct 1, 2016.

††7Т36-50 codes must include a sixth character=1, 2, 3, 4. Except: T36.9, T37.9, T39.9, T41.4, T42.7, T43.9, T45.9, T47.9, and T49.9 which must include a fifth character=1, 2.

ED visits and hospitalisations in 2010-2014 and in $89 \%$ of injury-related ED visits and hospitalisations in 2016.

\section{Analysis}

Weighted estimates of the number of older adult fall injuries and their corresponding 95\% CIs were calculated using SAS V.9.4 survey procedures to provide nationally representative estimates. Age-adjusted rates were calculated by applying age-specific rates to the 2000 US standard population age distribution. Revised trend weights were used for 2010 and 2011 NIS estimates to account for the change in NIS sampling that occurred in 2012. Two sample t-tests were used to calculate significant differences in age-adjusted ED and hospitalisation rates for fall injuries between 2010 and 2014 and and between 2014 and 2016.

\section{RESULTS}

In 2010, there were an estimated 1710294 ED visits for fall injuries among older adults resulting in an age-adjusted rate of 4187.9 ED visits per 100000 (95\% CI 4086.3 to 4289.6). This did not differ significantly in 2014 when there were 4288.3 ED

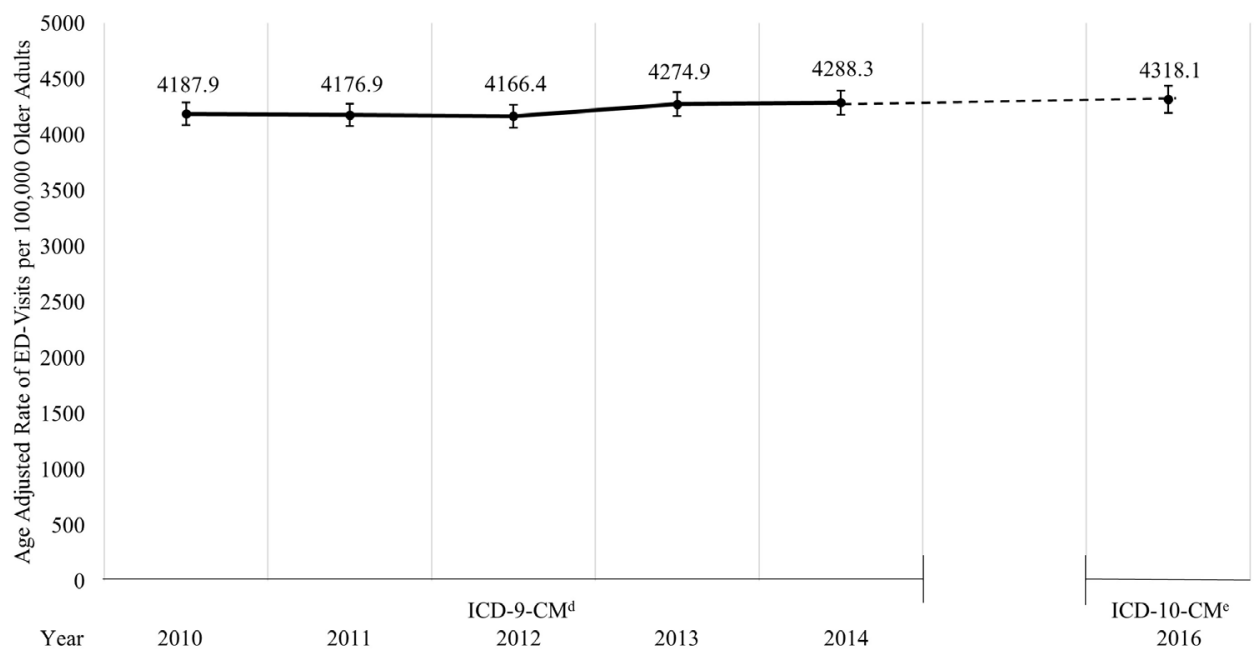

a Age-adjusted rates were calculated by applying age-specific rates to the 2000 U.S standard population age distribution.

${ }^{\mathrm{b}} \mathrm{ED}$ visits were limited to those with a disposition of treated and released at discharge.

c 2015 was excluded due to the transition from ICD-9-CM to ICD-10-CM occurring in that year

${ }^{d}$ International Classification of Diseases, Ninth Revision, Clinical Modification (ICD-9-CM).

' International Classification of Diseases, Tenth Revision, Clinical Modification (ICD-10-CM).

Figure 1 Age-adjusted ${ }^{a}$ rate of non-fatal fall injuries treated in emergency departments (EDs) ${ }^{b}$ among adults 65 years and older, Healthcare Cost and Utilisation Project-Nationwide Emergency Department Sample, USA, 2010-2014 and 2016 ${ }^{\mathrm{c}}$. 


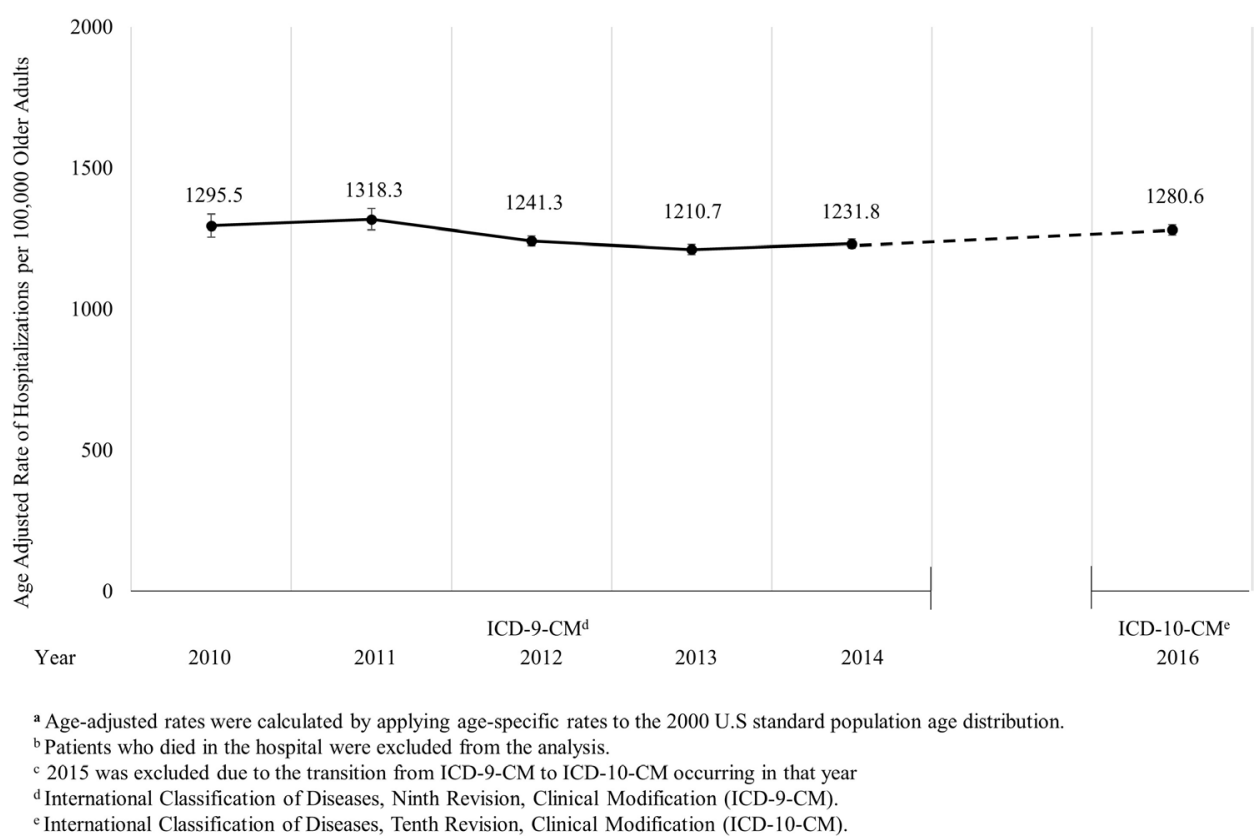

Figure 2 Age-adjusted ${ }^{\mathrm{a}}$ rate of hospital stays ${ }^{\mathrm{b}}$ for non-fatal fall-related injuries among adults 65 years and older, Healthcare Cost and Utilisation Project-National Inpatient Sample, USA, 2010-2014 and 2016.

visits for fall injuries per 100000 older adults $(95 \%$ CI 4180.8 to 4395.8) (figure 1). In 2016, there were an estimated 2069175 ED visits for fall injuries among older adults. The age-adjusted rate of ED visits for fall injuries in 2016 was 4318.1 per 100000 (95\% CI 4198.1 to 4438.1) which was not significantly different from the 2014 rate (figure 1).

There were an estimated 533560 hospitalisations for fall injuries among older adults in 2010. The age-adjusted rate of hospitalisations for fall injuries in 2010 (1295.5 per 100000 95\% CI 1254.1 to 1336.9 ) was significantly higher than 2014 (1231.8 per $10000095 \%$ CI 1215.0 to 1248.5 ) (figure 2). In 2016, there were an estimated 608290 hospitalisations for fall injuries among older adults. The age-adjusted rates of hospitalisations due to falls significantly increased between 2014 and 2016 (2016 rate: $1280.695 \%$ CI 1262.4 to 1298.8 ) (figure 2).

\section{DISCUSSION}

We did not identify significant changes in age-adjusted rates of fall-injury ED visits between 2014 and 2016 among older adults. There were significant changes in age-adjusted rates of fallrelated hospitalisations between 2014 and 2016. These results may potentially indicate that rates of hospitalisations for fall injuries increased between 2014 and 2016 or that the new classification system (ICD-10-CM) is capturing additional fall injuries compared with ICD-9-CM. Because we only looked at total fallrelated hospitalisations, we could not compare specific diagnosis rate changes during the classification transition.

ED visits for fall injuries did not differ between 2010 and 2014, however, the rate of hospitalisations for fall injuries was significantly lower in 2014 than 2010. This may be attributed to the change in sampling of NIS that occurred in 2012, which resulted in a one-time decrease in all hospital discharges. While trend weights were used to minimise this effect, ${ }^{12}$ the largest decrease in rates was between 2011 and 2012.

Previous research explored the effect of the transition to ICD-10-CM on surveillance of disease and injury. ${ }^{613-15}$ One study reported a significant increase in overall opioid-related hospitalisations after the 2015 transition, largely driven by hospitalisations for unspecified opioid use disorder which has no ICD-9-CM equivalent. ${ }^{13}$ However, ICD-9-CM already included a code for unspecified falls. Further analysis of individual codes is needed to confirm whether the number of falls coded as unspecified or falls coded with expanded injury specificity changed in relation to ICD-9-CM codes. Two additional papers used chart abstraction to determine the effect of implementing ICD-10-CA (Canadian modification) in Canada. ${ }^{14}{ }^{15}$ Quan et al ${ }^{14}$ reported little change in the documentation of chronic conditions, not including falls, using ICD-9-CA or ICD-10-CA; however, validity between coding revisions for some conditions differed when compared with chart abstraction. Karkhaneh $e t a l^{15}$ noted that both ICD-9-CA and ICD-10-CA misclassified some pedestrian injuries as falls. One additional study looked at the impact of the ICD-10-CM transition on injury hospitalisations in one US state (Kentucky). ${ }^{16}$ They did not report significant changes in the rate of fall-related hospitalisations before and after transition. ${ }^{16}$ Further analysis is needed to determine whether specific fall-related injuries are coded differently using ICD-10-CM.

The number of older Americans is expected to reach 74 million by $2030,{ }^{17}$ likely increasing the number of fall-related injuries. There is some evidence that the age-adjusted rate of fall deaths is increasing ${ }^{18}$ Evidence around non-fatal injury is, however, older and mixed. ${ }^{19}{ }^{20}$ In older adults, ED visits for fall injuries increased through $2010,{ }^{19}$ but hip fractures, a leading cause of fall-related hospitalisations, decreased through 2012 before plateauing. ${ }^{20}$ Continued surveillance is important to describe how the burden of falls changes over time.

This report has several limitations. First, our study focuses on older adult falls. Researchers interested in falls at younger ages may need to consider including additional codes. Second, codes were analysed in aggregate, after combining codes that specifically looked at fall injuries, and not individual codes. If there were changes in individual codes, these differences may not be detectable when combined. Third, this study did not estimate the sensitivity or specificity of ICD-10-CM. Future studies could use medical record review to determine the extent of changes in fall injury reporting due to the ICD-10-CM transition. Fourth, 
deaths that occurred in the ED or hospital were excluded, likely underestimating the burden of fall injuries. Fifth, the ICD-10-CM definition includes periprosthetic joint injuries, while the ICD-9-CM definition did not include these injuries. This may explain some differences in rates across the transition. Finally, identification of fall-related injuries depends on the presence of external-cause codes, which were not available for about $10 \%$ of visits potentially resulting in an undercounting of fallrelated injuries.

\section{CONCLUSION}

The transition does not appear to significantly impact the overall rates of fall-injury ED visits, but may have impacted the detected rates of hospitalisation for fall injuries among older adults. Results from future trend analyses of fall injury rates that span the ICD-9-CM to ICD-10-CM transition period should be interpreted cautiously. Additional research is needed to determine if the increase in hospitalisations from 2014 to 2016 is an artefact of the transition to ICD-10-CM, or due to an increase in fallrelated hospitalisations.

\section{What is already known on the subject?}

- The USA transitioned from the International Classification of Diseases, 9th Revision, Clinical Modification (ICD-9-CM) to the 10th Revision (ICD-10-CM) for clinical coding in medical settings in October 2015.

- Measuring rates of fall injuries in older adults requiring medical care over time is important in understanding the burden on the healthcare system and identifying any trends in falls and fall injuries.

\section{What this study adds?}

- The transition from International Classification of Diseases, Ninth Revision, Clinical Modification (ICD-9-CM) to ICD-10CM does not appear to significantly impact the rate of fallinjury emergency department visits among older adults but may have affected the rate of hospitalisations. More studies, including review of medical records, could better determine the impact of this transition.

Contributors BM designed the study, analysed the data, interpreted the data and led the writing. ERB helped conceive the study design, assisted with interpretation of the findings and revised the manuscript. YKH assisted in study design, interpreted the data and revised the manuscript.

Funding The authors have not declared a specific grant for this research from any funding agency in the public, commercial or not-for-profit sectors.

Disclaimer Its contents are solely the responsibility of the authors and do not necessarily represent the official views of the Centers for Disease Control and Prevention or the Department of Health and Human Services.

Competing interests None declared.

Patient and public involvement Patients and/or the public were not involved in the design, or conduct, or reporting, or dissemination plans of this research.

Patient consent for publication Not required.
Provenance and peer review Commissioned; externally peer reviewed.

Open access This is an open access article distributed in accordance with the Creative Commons Attribution Non Commercial (CC BY-NC 4.0) license, which permits others to distribute, remix, adapt, build upon this work non-commercially, and license their derivative works on different terms, provided the original work is properly cited, appropriate credit is given, any changes made indicated, and the use is non-commercial. See: http://creativecommons.org/licenses/by-nc/4.0/.

\section{ORCID iDs}

Briana L Moreland http://orcid.org/0000-0002-2144-1513

Yara K Haddad http://orcid.org/0000-0001-6803-2410

\section{REFERENCES}

1 Moreland B, Kakara R, Henry A. Trends in Nonfatal Falls and Fall-Related Injuries Among Adults Aged $\geq 65$ Years - United States, 2012-2018. MMWR Morb Mortal Wkly Rep 2020;69:875-81.

2 Centers for Disease Control and Prevention NCIPC. Web-Based injury statistics query and reporting system (WISQARS), 2015. Available: www.cdc.gov/injury/wisqars [Accessed Aug 2019].

3 Shumway-Cook A, Ciol MA, Hoffman J, et al. Falls in the Medicare population: incidence, associated factors, and impact on health care. Phys Ther 2009;89:324-32.

4 Outland B, Newman MM, William MJ. Health policy basics: implementation of the International classification of disease, 10th revision. Ann Intern Med 2015; 163:554-6.

5 Centers for Disease Control and Prevention NCHS. Classification of diseases, functioning and disability, 2019. Available: http://www.cdc.gov/nchs/icd.htm [Accessed Aug 2019].

6 Topaz M, Shafran-Topaz L, Bowles KH. ICD-9 to ICD-10: evolution, revolution, and current debates in the United States. Perspect Health Inf Manag 2013;10:1d.

7 Meyer H. Coding complexity: US health care gets ready for the coming of ICD-10. Health Aff 2011:30:968-74.

8 Hedegaard H, Johnson RL. An updated International classification of diseases, 10th revision, clinical modification (ICD-10-CM) surveillance case definition for injury hospitalizations. National health statistics reports; no 1252019.

9 CSTE Injury ICD-10-CM Transition Workgroup C. CSTE ICD-10-CM injury surveillance toolkit, 2019. Available: https://resources.cste.org/Injury-Surveillance-Methods-Toolkit [Accessed Feb 2020].

10 Injury Surveillance Workgroup. Consensus recommendations for using hospital discharge data for injury surveillance. Marietta (GA): state and territorial injury prevention directors association, 2003. Available: https://cdn.ymaws.com/www. safestates.org/resource/resm gr/imported/HospitalDischargeData.pdf

11 Centers for Disease Control and Prevention. Matrix of E-code groupings. Injury Prevention and Control 2014.

12 Agency for healthcare research and quality. Nationwide inpatient sample (NIS) redesign final report. Report \# 2014-04. Available: https://www.hcup-us.ahrq.gov/db/ nation/nis/reports/NIS_2012_Redesign_report.jsp

13 Heslin KC, Owens PL, Karaca Z, et al. Trends in Opioid-related inpatient stays shifted after the US Transitioned to ICD-10-CM diagnosis coding in 2015. Med Care 2017:55:918-23.

14 Quan H, Li B, Saunders LD, et al. Assessing validity of ICD-9-CM and ICD-10 administrative data in recording clinical conditions in a unique dually coded database. Health Serv Res 2008;43:1424-41.

15 Karkhaneh M, Hagel BE, Couperthwaite A, et al. Emergency department coding of bicycle and pedestrian injuries during the transition from ICD-9 to ICD-10. Inj Prev 2012;18:88-93.

16 Slavova S, Costich JF, Luu H, et al. Interrupted time series design to evaluate the effect of the ICD-9-CM to ICD-10-CM coding transition on injury hospitalization trends. Inj Epidemiol 2018;5:36.

17 Colby SL, Ortman JM. Projections of the size and composition of the US. population: 2014 to 2060, current population reports, P25-1143, U.S. census bureau, Washington, DC 2014.

18 Burns E, Kakara R. Deaths from falls among persons aged $\geq 65$ years - United States, 2007-2016. MMWR Morb Mortal Wkly Rep 2018;67:509-14.

19 DeGrauw X, Annest JL, Stevens JA, et al. Unintentional injuries treated in hospital emergency departments among persons aged 65 years and older, United States, 2006-2011. J Safety Res 2016;56:105-9.

20 Lewiecki EM, Wright NC, Curtis JR, et al. Hip fracture trends in the United States, 2002 to 2015. Osteoporos Int 2018;29:717-22. 